\title{
Adolescent Girls Empowerment Program (AGEP): Sexual and gender-based violence
}

\author{
Karen Austrian \\ Population Council \\ Erica Soler-Hampejsek \\ Natalie Jackson Hachonda \\ Population Council \\ Paul C. Hewett \\ Population Council
}

Follow this and additional works at: https://knowledgecommons.popcouncil.org/departments_sbsr-pgy

Part of the Demography, Population, and Ecology Commons, Domestic and Intimate Partner Violence Commons, Family, Life Course, and Society Commons, Gender and Sexuality Commons, and the International Public Health Commons

How does access to this work benefit you? Let us know!

\section{Recommended Citation}

Austrian, Karen, Erica Soler-Hampejsek, Natalie Jackson Hachonda, and Paul C. Hewett. 2018.

"Adolescent Girls Empowerment Program (AGEP): Sexual and gender-based violence," brief. Lusaka:

Population Council. 


\section{ADOLESCENT GIRLS EMPOWERMENT PROGRAM (AGEP): SEXUAL AND GENDER-BASED VIOLENCE}

Sexual and gender-based violence (SGBV) is a pervasive global health problem. Women and girls are most at risk, and consequences include physical injury, psychological trauma, unwanted pregnancy, and sexually transmitted infections, including HIV. ${ }^{1,2}$

The 2013-14 Zambia Demographic and Health Survey (ZDHS) $)^{3}$ found that $29 \%$ of 15 -19-year-old women and $42 \%$ of $20-24$-year-old women had experienced physical violence after age 15 . In addition, 8\% of 15-19 year olds and $16 \%$ of $20-24$-year-olds in Zambia have ever experienced some form of sexual violence, and $4 \%$ and $10 \%$, respectively, have experienced sexual violence in the past year. This proportion does not take into account sexual violence occurring to girls younger than age 15.

Girls and boys often internalize inequitable gender norms early in life, laying a foundation for unequal sexual relations. There is a correlation between such norms and the experience of violence. For example, women who agree that there are circumstances under which it is acceptable for a husband to beat his wife are more likely to report ever having experienced violence. ${ }^{4,5}$ In Zambia, $47 \%$ of women between the ages of 15 and 49 believe that intimate partner violence (IPV) is acceptable in certain circumstances. ${ }^{3}$

Interventions that aim to reduce the acceptability and experience of violence against women and girls offer a valuable end in itself, but such programs also serve as a means to improve additional health outcomes. The Adolescent Girls Empowerment Program is an example of such an intervention in Zambia.

\section{ADOLESCENT GIRLS EMPOWERMENT PROGRAM (AGEP)}

Through AGEP, the Population Council and partners implemented a social, health, and economic asset-building program in Zambia for over 11,000 vulnerable adolescent girls aged 10-19 years. The AGEP intervention was comprised of three major components: 1) weekly safe spaces groups in which girls met once a week for two years for training on sexual and reproductive health, life skills, and financial

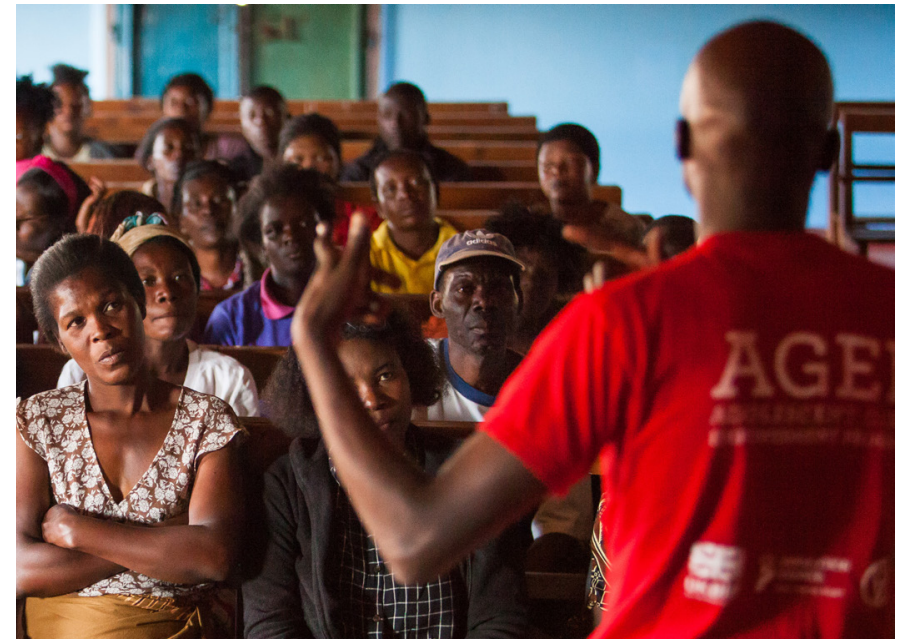

education; 2) a health voucher that girls could use at contracted private and public facilities for general wellness and sexual and reproductive health services; and 3) a savings account that was designed specifically to be girl-friendly. It was hypothesized that both the platform of the safe spaces groups-bringing girls together regularly, strengthening their self-esteem, and building support networks-would change gender norms and reduce violence. In addition, several sessions of the health and life skills curriculum directly focused on challenging inequitable gender norms, having healthy relationships and understanding, and preventing and responding to gender-based violence.

A randomized controlled trial (RCT) that was completed in 2017 evaluated the impact of AGEP on girls' acceptability of intimate partner violence (IPV), as well as experience of physical and sexual violence. Communities where AGEP was being implemented were randomly assigned different versions of the intervention-including safe spaces only, safe spaces with health vouchers, and the full program (safe spaces, health vouchers, and savings accounts). Data collected in 2015 represents the immediate impact of the program at the end of the two-year intervention. Data collected in 2017 allows for an assessment of impact two years after the end of the intervention. This brief focuses on the prevalence of acceptance of IPV and experience of SGBV among adolescent girls and young women in Zambia, as well as the effect of the AGEP intervention on those domains.

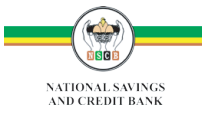




\section{RESULTS}

In the AGEP evaluation sample at baseline, 38\% of girls agreed that wife-beating was acceptable under certain circumstances. Interestingly, acceptance of IPV remained consistent across the five rounds of data collection, as the sample aged from 10-19 to $14-23$.

At baseline, more than $40 \%$ of girls aged $13-19$ had reported that they had experienced domestic violence and/or physical abuse in their lifetimes. Younger girls in urban settings were more likely to have experienced violence, compared to their rural counterparts; there was no difference in experience of violence between the older girls in urban and rural areas. Experience of physical violence among AGEP girls increased to $57 \%$ after two years post-baseline and almost two-thirds of girls had experienced physical violence after four years.

At baseline, one in five girls in the AGEP study sample aged 15-19a reported that they had been forced to have sexual intercourse or to perform other unwanted sexual acts. Over the course of the study, these figures changed to two out of five at midline and just over half at endline. ${ }^{b}$

Overall, the AGEP intervention reduced neither acceptability of IPV nor the experience of physical or sexual violence.

\section{CONCLUSION}

Acceptability and experience of sexual and gender-based violence is alarmingly high among adolescent girls in Zambia. Even more striking is the very young age from which notions of violence are ingrained and experience with violence begins. What we learn from the AGEP evaluation is that in the Zambian context, a program focused on changing norms among girls themselves is not enough to impact attitudes toward and experience of violence. Social and cultural norms are shaped by households, schools, communities, and all of the adults that girls interact with in these places-even the mentors of their own safe space groups. Therefore, it is likely that to change indicators on violence, work to change norms and underlying driving factors of violence needs to take place at the household and community levels, in addition to working with girls in groups to understand what violence is, why it is harmful, and why it is OK for them to aspire to a violence-free life in their school, household, and community.
- Acceptability and experience of sexual and gender-based violence among adolescent girls and young women in Zambia is alarmingly high.

- $\quad$ The AGEP intervention aimed to reduce acceptability and experience of violence among adolescent girls in Zambia through training sessions on gender norms, relationships, and SGBV, as well as building girls' self-esteem and economic assets.

- The program reduced neither acceptability nor experience of violence among adolescent girls.

- $\quad$ Future programs that aim to reduce SGBV among adolescents should address norms around violence at the household, school, and community levels, as well as work with adolescents directly.

\section{REFERENCES}

1. Campbell, J.C., M.L. Baty, R.M. Ghandour, J.K. Stockman, L. Francisco, and J. Wagman. 2008. "The intersection of intimate partner violence against women and HIV/AIDS: A review," International Journal of Injury Control and Safety Promotion 15(4): 221-231.

2. World Health Organization. 2013. "Global and regional estimates of violence against women: Prevalence and health effects of intimate partner violence and nonpartner sexual violence." World Health Organization.

3. Central Statistical Office (CSO), MOH [Zambia], and ICF International. 2014. Zambia Demographic and Health Survey 2013-2014. Rockville, MD, USA: CSO, MOH, and ICF international.

4. Jewkes, R. 2002. “Intimate partner violence: Causes and prevention,” The Lancet 359(9315): 1423-1429.

5. Gage, A.J. and P.L. Hutchinson. 2006. "Power, control, and intimate partner sexual violence in Haiti," Archives of Sexual Behavior 35(1): 11-24.

Authors: Karen Austrian, Erica Soler-Hampejsek, Natalie Jackson Hachonda, and Paul C. Hewett.

Only girls aged 15-19 in the study sample were asked questions about sexual violence.

We note that rates of sexual violence among the AGEP cohort are higher than rates in the DHS. This is likely because the AGEP cohort is made up of vulnerable girls in each site, while the DHS is nationally representative.

\section{CONTACT INFORMATION}

For more information about AGEP, call +260 211295925

or email: info@popcouncil.org

or visit: http://www.popcouncil.org/research/

adolescent-girls-empowerment-program
Population Council

Plot \#3670 No. 4 Mwaleshi Road

Olympic Park

Lusaka, Zambia 10101 